\title{
High Prevalence of Adrenal Insufficiency in Patients with Sickle Cell Disease: Results from a Community Hospital in the U.S.
}

Authors

Affiliation
J. Makino, A. Ndzengue, S. Adekolujo, A. Tipu, U. M. Dogar, H. Mezher, B. Sivasambu, D. Trauber, E. Guillaume, E. A. Jaffe, Z. Shiferaw-Deribe

Department of Medicine, Interfaith Medical Center, Brooklyn, NY, USA
Key words

- adrenal insufficiency

- sickle cell disease

- cosyntropin test

received 07.07.2012

first decision 09.10.2012

accepted $\quad 05.11 .2012$

Bibliography

DOI http://dx.doi.org/

10.1055/s-0032-1330036

Exp Clin Endocrinol Diabetes

2013; 121: 32-36

(c) J. A. Barth Verlag in Georg Thieme Verlag KG

Stuttgart · New York

ISSN 0947-7349

\section{Correspondence}

Dr. J. Makino, MD

Department of Medicine Interfaith Medical Center 1545 Atlantic Avenue Brooklyn

NY 11213

USA

Tel.: Primary: 718/613/4063

Secondary: 347/512/3166

Fax: 718/613/4893

drjunmakino@gmail.com

JunMakino@interfaithmedical.org

\section{Abstract}

$\nabla$

Objective: Despite the low prevalence $(0.008 \%)$ of adrenal insufficiency (AI) in the general population, this disorder was recently diagnosed in a substantial number of sickle cell disease (SCD) patients at our hospital. The main objective of this study was to assess the prevalence of $\mathrm{AI}$ in SCD patients.

Methods: All adult patients admitted to the Department of Medicine at Interfaith Medical Center from October 2010 to November 2011 were eligible for this retrospective study. Medical records of adult SCD patients hospitalized for painful crisis and who had undergone cosyntropin testing were reviewed. Adult non-SCD patients hospitalized for painful crisis and who had undergone cosyntropin testing served as controls. The result of the cosyntropin test was

\section{Introduction}

Adrenal insufficiency (AI) is a condition in which the adrenal glands do not produce adequate amounts of cortisol. It is a rare disorder that affects about 8 in $100000(0.008 \%)$ adults [1] Clinical symptoms include weakness, dizziness, low blood pressure, and hypoglycemia; however, the onset is usually insidious, and in such cases, plasma sodium and potassium abnormalities may be the only indicators of the disease. Recently, AI was diagnosed in a substantial number of patients at our hospital. Most of the affected patients had sickle cell disease (SCD) and had been admitted for sickle cell painful crisis management. The workup for AI is invariably triggered by findings of low blood pressure or electrolyte abnormalities without signs of sepsis, dehydration, or myocardial infarction. The aim of our study was to assess the prevalence of AI in SCD patients retrospectively by reviewing their medical records. the primary outcome. The prevalence of positive cosyntropin tests was compared between the 2 groups by using Student's $t$-test, and odds ratios. Results: 62 adult SCD patients were enrolled in the study. 15 underwent cosyntropin testing and $12(19.4 \%)$ of these patients were found to have AI. AI was also diagnosed in 1 of 1340 non-SCD patients. The odds ratio for AI in SCD to non-SCD patients $[(12 / 62) /(1340)]$ was 259 . The odds ratio for the prevalence of $\mathrm{AI}$ in SCD patients in our study (19.4\%) vs. the general population (approximately $0.008 \%$ ) was 2375 .

Conclusion: AI occurred in $19.4 \%$ of SCD patients included in this study. These patients thus have a 2375-fold higher risk of developing AI than the general population, and a 259-fold greater risk of developing AI than do hospitalized non-SCD patients.

\section{Subjects and Methods}

$\nabla$

\section{Patients}

The Interfaith Medical Center is a 287-bed community-based hospital in New York City. All adult patients (aged 18 years or older) hospitalized to the medical floor at the Interfaith Medical Center, between October 24, 2010, and November 23, 2011, were eligible for this retrospective study.

\section{Inclusion criteria}

Medical records of adult SCD patients (confirmed by hemoglobin electrophoresis) that were hospitalized for painful crisis, had low morning cortisol levels, and had undergone cosyntropin testing were reviewed. Medical records of adult non-SCD patients that were hospitalized for painful crisis, that is, any type of pain as a chief complaint, and who likewise underwent cosyntropin testing were also selected and used as controls. 


\begin{tabular}{|c|c|c|c|c|c|}
\hline & \multicolumn{2}{|l|}{ SCD } & \multicolumn{2}{|l|}{ Non-SCD (Control) } & p-value \\
\hline number of Patients & \multicolumn{2}{|l|}{62} & \multicolumn{2}{|l|}{3} & $\mathrm{~N} / \mathrm{A}$ \\
\hline age (Median years) & \multicolumn{2}{|l|}{$32.2 \pm 10.6$} & \multicolumn{2}{|l|}{$27.7 \pm 4.2$} & $P=0.45$ \\
\hline female Gender (\%) & \multicolumn{2}{|l|}{ 38/62 (61\%) } & \multicolumn{2}{|l|}{$0 / 3(0 \%)$} & N/A \\
\hline Race (\%) & \multicolumn{2}{|l|}{-} & \multicolumn{2}{|l|}{-} & $\mathrm{N} / \mathrm{A}$ \\
\hline black & \multicolumn{2}{|l|}{$58 / 62$ (94\%) } & \multicolumn{2}{|l|}{$3 / 3(100 \%)$} & - \\
\hline white & \multicolumn{2}{|l|}{$3 / 62(5 \%)$} & \multicolumn{2}{|l|}{$0 / 3(0 \%)$} & - \\
\hline others & \multicolumn{2}{|l|}{$1 / 62(1 \%)$} & \multicolumn{2}{|l|}{$0 / 3(0 \%)$} & - \\
\hline \multirow[t]{4}{*}{ underlying Disease } & Hb-SS 33 & $33(53 \%)$ & Substance Abuse & $1(33 \%)$ & $\mathrm{N} / \mathrm{A}$ \\
\hline & Beta-Thalassemia & $14(23 \%)$ & HIV/AIDS & $1(33 \%)$ & - \\
\hline & $\mathrm{Hb}-\mathrm{SC}$ & $9(15 \%)$ & HIV/AIDS & $1(33 \%)$ & - \\
\hline & Other & $6(10 \%)$ & & & - \\
\hline
\end{tabular}

Table 1 General Demographic

Characteristics of Patients.

\section{Exclusion criteria}

Patients younger than 18 years and those who had been treated with steroids for any reason other than AI within the last year were excluded from the study. Adult SCD patients hospitalized for painful crisis whose morning serum cortisol levels were greater than $18 \mu \mathrm{g} / \mathrm{dL}$ (exclusion criteria for $\mathrm{AI}$ ) were excluded.

\section{Study variables}

The primary study variable was the result of cosyntropin tests. Secondary variables were: the doses of opioids administered during index admission, results of iron studies, and numbers of red blood cells units transfused over the previous year. Other covariables were gender, age, genotype of sickle cell hemoglobinopathy, mean corpuscular volume (MCV), reticulocyte count, lactose dehydrogenase (LDH) levels, and blood pressure on test date.

Morning serum cortisol levels were measured between $0600 \mathrm{~h}$ and $0800 \mathrm{~h}$ for screening tests, and the results were analyzed as described below. AI was confirmed if the morning serum cortisol level were less than $3 \mu \mathrm{g} / \mathrm{dL}$ [2-4]. Diagnosis of AI was ruled out if morning serum cortisol levels were greater than $18 \mu \mathrm{g} / \mathrm{dL}$ $[2,5]$. For the patients whose morning serum cortisol levels were between 3 and $18 \mu \mathrm{g} / \mathrm{dL}$, cosyntropin tests were subsequently conducted. Morning serum cortisol levels and plasma adrenocorticotropic (ACTH) levels were measured before administration of medication, and then serum cortisol levels were measured again 30 and $60 \mathrm{~min}$ after the administration of an intravenous bolus of $250 \mu \mathrm{g}$ of ACTH. Responses were considered normal if maximum serum cortisol levels measured after bolus administration were greater than $18 \mu \mathrm{g} / \mathrm{dL}[6,7]$. Once AI was confirmed by cosyntropin testing, patients were categorized as having primary or secondary AI on the basis of baseline plasma ACTH levels. AI was considered primary if plasma ACTH levels were high ( $>63.3 \mathrm{pg} / \mathrm{mL}$ ) and considered secondary or tertiary if plasma ACTH levels were low or inappropriately normal $(<63.3 \mathrm{pg} / \mathrm{mL})$. Computed tomography (CT) or magnetic resonance imaging (MRI) scans of the brain and the pituitary glands were reviewed to investigate the etiology of secondary and tertiary AI. The corticotropin-releasing hormone ( $\mathrm{CRH})$ stimulation test is used to differentiate between secondary and tertiary AI. However, since secondary and tertiary adrenal insufficiencies are treated similarly, the CRH stimulation test was not performed. All hormonal test results were reviewed and confirmed by an experienced endocrinologist. The study was conducted after approval by the Institutional Review Board (IRB) at Interfaith Medical Center.

\section{Assays}

All parameters were measured using commercially available radioimmunofocus assays (RIAs) or immunoradiometric assays.
The sensitivity of the ACTH assay (ACTH Immunoassay, Roche Diagnostics, Indianapolis, IN, USA) was $1.0 \mathrm{pg} / \mathrm{mL}$. The intra-assay coefficients of variation were $2.7 \%$ at $4.9 \mathrm{pg} / \mathrm{mL}$ and $0.7 \%$ at $1205 \mathrm{pg} / \mathrm{mL}$. The normal value for plasma ACTH is $7.2-63.3 \mathrm{pg} / \mathrm{mL}$. The sensitivity of the cortisol assay (Roche Diagnostics, Indianapolis, IN, USA) was $0.03 \mu \mathrm{g} / \mathrm{dL}$. The intra-assay coefficient of variation was $1.7 \%$ at $4.69 \mu \mathrm{g} / \mathrm{dL}$ and $1.7 \%$ at $26.0 \mu \mathrm{g} / \mathrm{dL}$. The normal value for serum cortisol is $6.2-19.4 \mu \mathrm{g} / \mathrm{dL}$ at $0800 \mathrm{~h}$ and $2.3-$ $11.9 \mu \mathrm{g} / \mathrm{dL}$ at $2000 \mathrm{~h}$.

\section{Statistical analysis}

Comparisons of positive cosyntropin tests and secondary variables were compared using Student's t-test. A p value of less than 0.05 was considered statistically significant. The odds ratio for positive cosyntropin tests were calculated.

\section{Results}

$\nabla$

A total of 4053 adult patients were hospitalized in the Department of Medicine at Interfaith Medical Center between October 23, 2010, and November 23, 2011. 62 SCD patients were hospitalized for painful crisis; their general demographic characteristics are shown in 0 Table 1. Morning serum cortisol levels were measured in 17 of these 62 SCD patients ( Fig. 1 shows schematic diagram of the study design). These patients were selected on the basis of low blood pressure readings and electrolyte abnormalities. Cortisol levels were lower than $18 \mu \mathrm{g} / \mathrm{dL}$ in all 17 patients. Cosyntropin tests were performed in 15 of the above 17 SCD patients (mean morning cortisol level of $5.4 \pm 4.5 \mu \mathrm{g} / \mathrm{dL}$ ). Test results were suggestive of $\mathrm{AI}$ in 12 patients (19.4\%; 12 of 62 SCD patients) ( $\odot$ Table 2). Mean serum cortisol levels 30 and $60 \mathrm{~min}$ after ACTH stimulation were low: $8.8 \pm 5.3 \mu \mathrm{g} / \mathrm{dL}$ (30 min) and $13.4 \pm 3.1 \mu \mathrm{g} / \mathrm{dL}(60 \mathrm{~min})$ in the positive test group (normal: greater than $18 \mu \mathrm{g} / \mathrm{dL}$ ). Baseline plasma ACTH levels were either low or inappropriately normal in all 12 positive test-group patients (mean: $11.4 \pm 7.7 \mathrm{pg} / \mathrm{mL}$; normal: 7.2-63.3 pg/mL). These patients were categorized as having secondary AI. Of the 12 patients with secondary AI, none had a history of head injury in the past. 8 patients had undergone MRIs or CTs of the brain and pituitary gland. The results were negative for hypothalamic or pituitary hemorrhage, infarct, or mass for all 8 patients. When SCD patients with and without AI were compared, MCV values were significantly greater in SCD patients with AI than in SCD patients without $\mathrm{AI}(85.3 \pm 14.6 \mathrm{vs}$. 99.7 \pm 7.9 ; $\mathrm{p}<0.05)$. In contrast, many clinical parameters did not differ significantly between AI patients with SCD. These parameters included: reticulocyte count upon admission $(12.3 \pm 15.2$ cells $/ \mu \mathrm{L}$ vs. $10.0 \pm 5.1$ cells $/ \mu \mathrm{L}$; $\mathrm{p}=0.68)$, LDH level upon admission $(311.3 \pm 145.7 \mathrm{IU} / \mathrm{L}$ vs. 


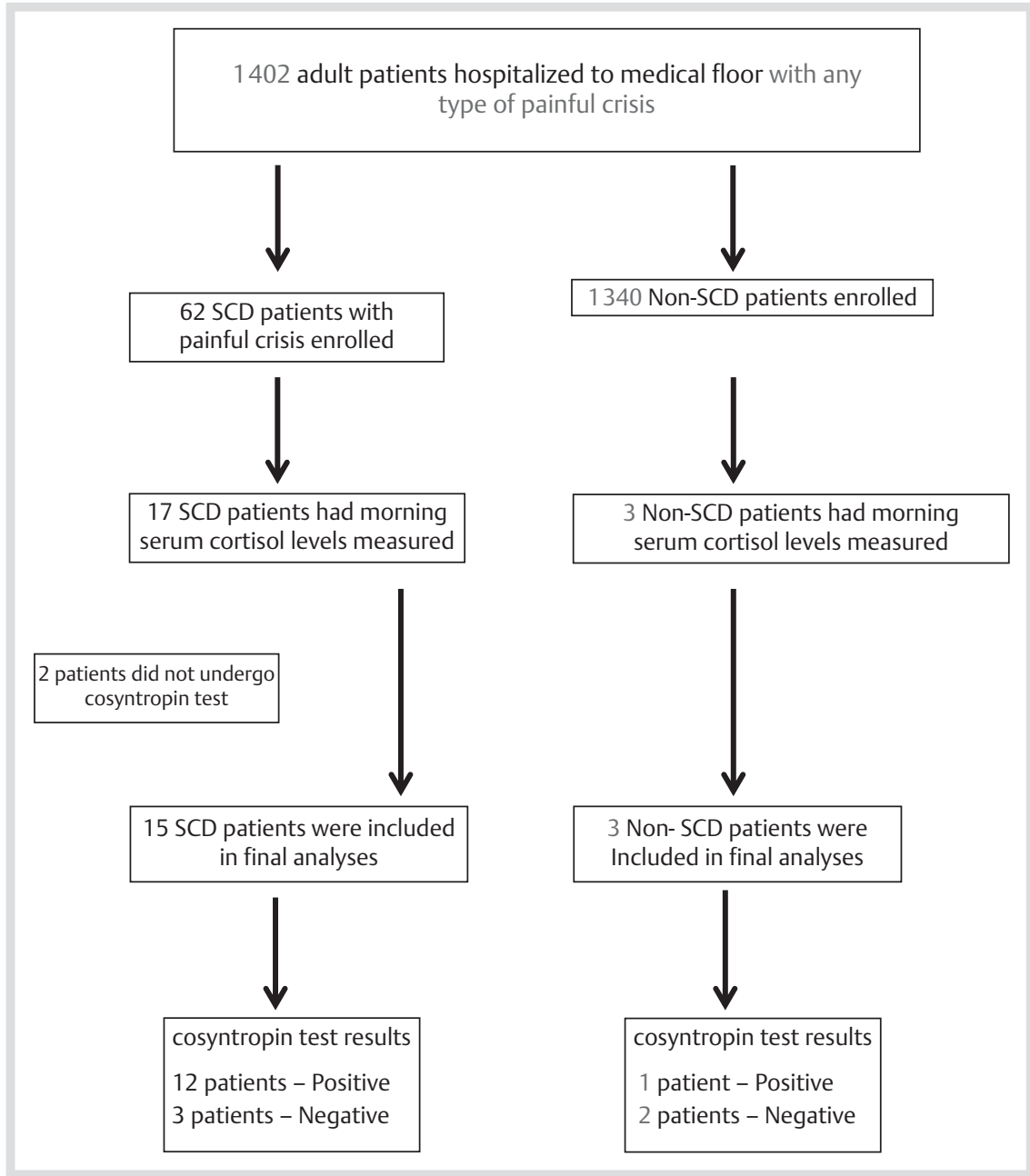

Fig. 1 Schematic Diagram of the Study Design.

Table 2 High-dose ACTH Stimulation (Cosyntropin) Test Results.

\begin{tabular}{|c|c|c|c|c|c|c|c|c|c|}
\hline & & $\begin{array}{l}\text { \# of } \\
\text { Patients }\end{array}$ & $\begin{array}{l}\text { Morning } \\
\text { Cortisol }\end{array}$ & p-value & Baseline ACTH & p-value & $\begin{array}{l}\text { Cortisol } \\
30 \mathrm{~min}\end{array}$ & $\begin{array}{l}\text { Cortisol } \\
60 \mathrm{~min}\end{array}$ & p-value \\
\hline \multicolumn{2}{|c|}{ Reference Range } & & $6.7-22.6 \mu \mathrm{g} / \mathrm{mL}$ & - & $7.2-63.3 \mu \mathrm{g} / \mathrm{mL}$ & - & $>18 \mu \mathrm{g} / \mathrm{dL}$ & $>18 \mu \mathrm{g} / \mathrm{dL}$ & - \\
\hline SCD & normal (A) & 3 & $9.0 \pm 6.7$ & $\begin{array}{l}\text { A vs. B: } \\
p<0.05\end{array}$ & $12.5 \pm 7.3$ & $\begin{array}{l}\text { A vs. B: } \\
p=0.83\end{array}$ & $\mathrm{~N} / \mathrm{A}$ & $20.4 \pm 2.1$ & $\begin{array}{l}\text { A vs. B: } \\
p<0.005\end{array}$ \\
\hline SCD & $\mathrm{Al}\left({ }^{*}\right)(\mathrm{B})$ & 12 & $3.6 \pm 2.1$ & $\begin{array}{l}\text { C vs. D: } \\
\text { N/A }\end{array}$ & $11.4 \pm 3.1$ & $\begin{array}{l}\text { C vs. D: } \\
\text { N/A }\end{array}$ & $8.8 \pm 5.3$ & $13.4 \pm 3.1$ & $\begin{array}{l}\text { Cvs. D: } \\
\text { N/A }\end{array}$ \\
\hline Non-SCD & Normal (C) & 2 & 11.8 & $\begin{array}{l}\text { B vs. D: } \\
\text { N/A }\end{array}$ & 27.0 & $\begin{array}{l}\text { B vs. D: } \\
\text { N/A }\end{array}$ & $\mathrm{N} / \mathrm{A}$ & 30.7 & $\begin{array}{l}\text { B vs. D: } \\
\text { N/A }\end{array}$ \\
\hline Non-SCD & $\mathrm{Al}\left({ }^{*}\right)(\mathrm{D})$ & 1 & 6.2 & $\begin{array}{l}\text { A vs. C: } \\
P=0.7\end{array}$ & 1.0 & $\begin{array}{l}\text { A vs. C: } \\
P=0.44\end{array}$ & $\mathrm{~N} / \mathrm{A}$ & 14.2 & $\begin{array}{l}\text { A vs. C: } \\
P=0.69\end{array}$ \\
\hline
\end{tabular}

$\left({ }^{*}\right)$ Al = Adrenal Insufficiency

$363.9 \pm 206.2 \mathrm{IU} / \mathrm{L} ; \mathrm{p}=0.69)$, potassium level on test date $(4.4 \pm 0.5 \mathrm{mEq} / \mathrm{L}$ vs. $4.3 \pm 0.3 \mathrm{mEq} / \mathrm{L} ; \mathrm{p}=0.50)$, transferrin saturation $(55.8 \pm 20.7 \%$ vs. $38.0 \pm 9.9 \%$; $=0.29)$, units of red blood cells transfused ( $2.7 \pm 4.6$ units vs. $6.4 \pm 8.1$ units; $p=0.48)$, and the doses of opioids administered during the admission $(3.9 \pm 3.4 \mathrm{mg} /$ $\mathrm{kg} /$ day vs. $4.6 \pm 2.7 \mathrm{mg} / \mathrm{kg} /$ day; $\mathrm{p}=0.71$ ) ( Table 3 ).

Thyroid stimulating hormone (TSH) levels were also measured in 11 of the 12 SCD patients with AI. The levels were normal in all but one patient: $1.8 \pm 1.2 \mu \mathrm{IU} / \mathrm{mL}$ (normal: $0.34-5.6 \mu \mathrm{IU} / \mathrm{mL}$ ). The exception was 1 patient with low TSH level $(0.33 \mu \mathrm{IU} / \mathrm{mL})$. Aside from TSH levels, other pituitary hormone level including prolactin, insulin-like growth factor (IGF-1), follicular stimulating hormone (FSH), and luteinizing hormone ( $\mathrm{LH})$ were also measured in a few of these patients, but the results were incomplete. In addition, the hypothalamic-pituitary-adrenal axes were not reassessed in these 12 patients after index admission.

Of the 3 non-SCD patients whose morning serum cortisol levels were measured, 3 fulfilled the inclusion criteria. Cosyntropin testing was subsequently conducted for these patients ( $\bullet$ Fig. 1). Results were suggestive of AI in 1 ( $\bullet$ Table 2 ). In other words, 1 of 1340 non-SCD patients $(0.075 \%)$ fulfilled the clinical criteria for AI.

The odds ratio for AI [(12/62)/(1/1340)] was 259 in SCD and non-SCD patients. When the prevalence of AI in SCD patients was compared to that of the general population, the odds ratio $[(19.4 \%) /(0.008 \%)]$ was 2375 . 
Table 3 Clinical, Laboratory, and Treatment Variables in Study Groups.

\begin{tabular}{|c|c|c|c|c|c|c|c|}
\hline Patients group (SCD vs. Non-SCD) & Normal Range & SCD & SCD & D-value & Non-SCD & Non-SCD & D-value \\
\hline patients & & $3 / 62(4.8 \%)$ & $12 / 62(19.4 \%)$ & & 2 & 1 & \\
\hline female & & $3 / 3(100 \%)$ & $7 / 12(58 \%)$ & & 0 & 0 & \\
\hline age (yr) & & $39.3 \pm 12.2$ & $33.1 \pm 10.2$ & $p=0.39$ & 30 & 23 & $\mathrm{~N} / \mathrm{A}$ \\
\hline genotype: Hb SS & & $2 / 3(67 \%)$ & $10 / 12(83 \%)$ & & & & \\
\hline $\mathrm{Hb}$ S- $\beta+$ thalassemia & & $1 / 3(33 \%)$ & $1 / 12(8.3 \%)$ & & & & \\
\hline $\mathrm{Hb} \mathrm{SC}$ & & $0 / 3(0 \%)$ & $1 / 12(8.3 \%)$ & & & & \\
\hline MBP on test date $(\mathrm{mmHg})$ & & $79.0 \pm 19.1$ & $73.7 \pm 8.5$ & $p=0.47$ & 85 & 56 & N/A \\
\hline systolic BP on test date $(\mathrm{mmHg})$ & & $103.0 \pm 22.9$ & $101.5 \pm 13.6$ & $p=0.89$ & 109 & 83 & $\mathrm{~N} / \mathrm{A}$ \\
\hline $\mathrm{Na}$ on test date $(\mathrm{mEq} / \mathrm{L})$ & $136-144$ & $135.3 \pm 2.5$ & $136.7 \pm 2.3$ & $p=0.40$ & 125 & 139 & N/A \\
\hline $\mathrm{K}$ on test date (mEq/L) & $3.6-5.1$ & $4.4 \pm 0.5$ & $4.3 \pm 0.3$ & $p=0.50$ & 4.5 & 4.5 & $\mathrm{~N} / \mathrm{A}$ \\
\hline Glu on test date $(\mathrm{mg} / \mathrm{dL})$ & $74-118$ & $90.3 \pm 38.1$ & $105.4 \pm 33.0$ & $p=0.52$ & 93 & 100 & $\mathrm{~N} / \mathrm{A}$ \\
\hline iron $(\mathrm{mcg} / \mathrm{dL})$ & $45-182$ & $103.4 \pm 63.7$ & $115.5 \pm 33.2$ & $p=0.81$ & $\mathrm{~N} / \mathrm{A}$ & $\mathrm{N} / \mathrm{A}$ & \\
\hline ferritin $(\mathrm{ng} / \mathrm{mL})$ & $11-307$ & $1632.9 \pm 1731.1$ & $1179.0 \pm 1558.5$ & $p=0.74$ & $\mathrm{~N} / \mathrm{A}$ & $\mathrm{N} / \mathrm{A}$ & \\
\hline transferrin saturation (\%) & $20-50$ & $55.8 \pm 20.7$ & $38.0 \pm 9.9$ & $p=0.29$ & $\mathrm{~N} / \mathrm{A}$ & $\mathrm{N} / \mathrm{A}$ & \\
\hline $\mathrm{MCV}(\mathrm{fL})$ & $80-100$ & $85.3 \pm 14.6$ & $99.7 \pm 7.9$ & $p<0.05$ & $\mathrm{~N} / \mathrm{A}$ & $\mathrm{N} / \mathrm{A}$ & \\
\hline reticulocyte count & $0.5-1.5$ & $12.3 \pm 15.2$ & $10.0 \pm 5.1$ & $p=0.68$ & $\mathrm{~N} / \mathrm{A}$ & $\mathrm{N} / \mathrm{A}$ & \\
\hline $\mathrm{LDH}(\mathrm{IU} / \mathrm{L})$ & 98-192 & $311.3 \pm 145.7$ & $363.9 \pm 206.2$ & $p=0.69$ & $\mathrm{~N} / \mathrm{A}$ & $\mathrm{N} / \mathrm{A}$ & \\
\hline morphine sulfate (mg/kg/day) & & $3.9 \pm 3.4$ & $4.6 \pm 2.7$ & $p=0.71$ & $\mathrm{~N} / \mathrm{A}$ & $\mathrm{N} / \mathrm{A}$ & \\
\hline units of red cells transfused/year & & $2.7 \pm 4.6$ & $6.4 \pm 8.1$ & $p=0.48$ & $\mathrm{~N} / \mathrm{A}$ & $\mathrm{N} / \mathrm{A}$ & \\
\hline
\end{tabular}

*1. Al: Adrenal Insufficiency

\section{Discussion}

In spite of the low prevalence of AI in the general population (0.008\%), this disorder was diagnosed in $19.4 \%$ of patients with SCD in our retrospective analysis. SCD is an autosomal recessive hemoglobin disorder characterized by hemolytic anemia and intermittent occlusion of small vessels by sickling cells. This occlusion eventually leads to chronic organ damage and dysfunction [8].

There are few reports focusing on AI in SCD patients. The prevalence and pathogenesis of $\mathrm{AI}$ in SCD patients are therefore not clear $[9,10]$. Iron overload-induced endocrinopathy, vaso-occlusion/ischemia-induced endocrinopathy, and opioid-induced HPA axis dysfunction have all been considered as potential causes of AI in SCD patients [11-20].

Endocrinopathies, including AI, are among the earliest manifestations of iron overload syndrome secondary to multiple red blood cell transfusions (more than 8 units in a 12 month period) in SCD patients [11,12]. Iron overload syndrome is a condition in which excess iron from dietary or multiple transfusions accumulates in the body and causes damage to organs. Cardiomyopathy, cirrhosis, endocrinopathy and diabetes mellitus have all been reported as examples of organ damage secondary to iron accumulation. According to previous studies, a transferrin saturation greater than $60 \%$ in men and $50 \%$ in women diagnoses iron overload syndrome in more than $90 \%$ of patients $[13,14]$. In our study, 6 of our 12 SCD patients with AI had iron overload syndrome, based on their high transferrin saturation levels. However, transferrin saturation levels were normal in the remaining 6 patients. These data indicates that iron overload is not the sole contributor to AI in SCD patients.

Vaso-occlusion-induced ischemia has been implicated in the pathogenesis of endocrine dysfunction in SCD. Vaso-occlusion with or without infarction of the involved organs is not uncommon and may involve any internal organs. These organs include the brain, the pituitary gland, and the adrenal glands in SCD patients $[15,16]$. All cases of AI in SCD patients in this study were of central origin (secondary to pituitary or hypothalamic dysfunction), as demonstrated by low or inappropriately normal baseline ACTH levels. Athanasou reported a case of SCD in which recent necrosis of the pituitary gland was seen upon necropsy. These data supports the above hypothesis [17]. Rosenbloom et al. noted that baseline serum cortisol levels were low in SCD patients and dropped further during vaso-occlusive crisis. These data were consistent with vaso-occlusion-induced stepwise decline in HPA axis function $[10,18]$. The finding that SCD patients had normal potassium levels and low or inappropriately normal baseline plasma ACTH levels suggests that the hypothalamo-pituitary complex is the main target for vaso-occlusioninduced ischemia, although MRI studies of the pituitary in SCD with AI were negative.

A possible cause of secondary AI in our SCD patients could be chronic use of opioid analgesics, as has previously been suspected by other authors $[3,4,19]$. Schimke reported a case of secondary AI induced by chronic use of opioids for pain management [19]. Opiates bind $\mu$ and $\mathrm{k}$-opioid receptors and exert stimulatory effects on the HPA axis. Over time, however, the HPA axis develops tolerance to the stimulatory effects of opioid agonists, and ultimately opiates inhibit the release of corticotropinreleasing factor (CRF) from the hypothalamus [20]. A subsequent decrease in ACTH production by CRF will eventually lead to low cortisol levels. The dose-ranges and duration of opioid analgesics use required to cause secondary AI are still unknown, as is the duration of the resultant HPA axis dysfunction.

Our study has some limitations. First, our study was retrospective, and the number of patients analyzed was limited. Therefore, larger studies are required in order to confirm our results. Second, cortisol levels 30 min after high-dose ACTH stimulation tests were not measured in all patients, and thus the calculated mean may not reflect the peak cortisol level. Third, CTs or MRIs of the pituitary gland and hypothalamus were not done in all patients with secondary AI. Therefore, hemorrhagic necrosis of the pituitary gland or hypothalamus cannot be ruled out in all of our patients. Fourth, it was difficult to determine the precise dose of opioids taken before the index admission. As a result, we could not characterize the pattern of opioid use that best corre- 
lated with the occurrence of AI. Fifth, pituitary hormone levels other than ACTH levels were not measured in all SCD patients with AI. We therefore, could not conclude if other components of the pituitary axis might also be affected or not. Finally, we did not determine whether the HPA-axis dysfunction was transient or persistent.

\section{Conclusion}

$\nabla$

Our retrospective analysis confirmed AI in $19.4 \%$ of SCD patients tested. These patients therefore had a 2375-fold risk of AI compared with the general population, and a 259-fold risk of AI compared with a hospitalized non-SCD population. Our study suggests that AI in SCD patients is generally secondary to hypothalamic or pituitary dysfunction. Since chronic opioid use is known to induce AI, chronic opioid use in our SCD patients may well be an instigating factor. Larger, in-depth studies are needed to determine the prevalence and pathogenesis of $\mathrm{AI}$ more accurately in SCD patients.

\section{Conflict of Interest and Acknowledgements \\ $\nabla$}

The authors thank all study participants and the Department of Medicine research staff for their contribution to the study. There is nothing to declare with regard to conflicting interests or financial disclosure.

\section{References}

1 Springhouse Professional Guide to Diseases (Eighth Edition). Lippincott Williams \& Wilkins, 2005

2 Smiley D, Dagogo-Jack S, Umpierrez G. Therapy Insight: metabolic and endocrine disorders in sickle cell disease. Nat Clin Pract Endocrinol Metab 2008; 4 (2): 102-109

3 Müssig K, Knaus-Dittmann D, Häring $H U$ et al. Secondary adrenal failure and secondary amenorrhoea following hydromorphone treatment. Clin Endocrinol (Oxf) 2007; 66: 604-605
4 Oltmanns KM, Fehm HL, Peters A. Chronic fentanyl application induces adrenocortical insufficiency. J Intern Med 2005; 257 (5): 478-480

5 Jenkins $D$, Forsham PH, Thorn GW et al. Use of ACTH in the diagnosis of adrenal cortical insufficiency. Am J Med 1955; 18 (1): 3-14

6 Watts NB, Tindall GT. Rapid assessment of corticotropin reserve after pituitary surgery. JAMA 1988; 259 (5): 708-711

7 Dickstein G, Shechner C, Lahav $M$ et al. Adrenocorticotropin stimulation test: effects of basal cortisol level, time of day, and suggested new sensitive low dose test. J Clin Endocrinol Metab 1991; 72 (4): 773-778

8 Ballas SK. Sickle cell anaemia: progress in pathogenesis and treatment. Drugs 2002; 62 (8): 1143-1172

9 Osifo BO, Lukanmbi FA, Adekile A. Plasma cortisol in sickle cell disease. Acta Haematol 1988; 79 (1): 44-45

10 Rosenbloom BE, Odell WD, Tanaka KR. Pituitary-adrenal axis function in sickle cell anemia and its relationship to leukocyte alkaline phosphatase. Am J Hematol 1980; 9 (4): 373-379

11 Olivieri NF. Progresssion of iron overload in sickle cell disease. Semin Hematol 2001; 38 (Suppl 1): 57-62

12 Fung EB, Harmatz PR, Vichinsky EP et al. Multi-Centre Study of Iron Overload Research Group. Increased prevalence of iron-overload associated endocrinopathy in thalassaemia versus sickle cell disease. $\mathrm{Br} \mathrm{J}$ Haematol 2006; 135 (4): 574-582

13 Edwards CQ, Kushner JP. Screening for hemochromatosis. N Engl J Med 1993; 328 (22): 1616-1620

14 Pippard MJ. Detection of iron overload. Lancet 1997; 349 (9045): 73-74

15 Kimmelstiel P. Vascular occlusion and ischemic infarction in sickle cell disease. Am J Med Sci 1948; 216 (1): 11-19

16 Diggs LW. Anatomic lesions in sickle cell disease. In: Abramson IT, Bertles JF, Wethers DL (eds.). Sickle cell disease. Diagnosis, management, education and research. St Louis: CV Mosby Co, 230, 1973

17 Athanasou NA, Hatton C, Weatherall DJ et al. Vascular occlusion and infarction in sickle cell crisis and the sickle chest syndrome. J Clin Pathol 1985; 38 (6): 659-664

18 Hargreaves KM. Neuroendocrine markers of stress. Anesth Prog 1990; 37 (2-3): 99-105

19 Schimke KE, Greminger P, Brändle M. Secondary adrenal insufficiency due to opiate therapy - another differential diagnosis worth consideration. Exp Clin Endocrinol Diabetes 2009; 117 (10): 649-651 Epub 2009 Apr 16

20 Sarnyai Z, Shaham Y, Heinrichs SC. The role of corticotropin-releasing factor in drug addiction. Pharmacol Rev 2001; 53 (2): 209-243 